Original Research Paper

\title{
The Hanshaw Helm-Stevens Rapid Prototype Instructional Design Model: Examining the Dimensions of Structure and Dialogue within the Framework of Higher Education
}

\author{
Roxanne Helm-Stevens, George Hanshaw and Joseph Kim \\ Azusa Pacific University California, USA
}

Article history

Received: 10-01-2019

Revised: 01-04-2019

Accepted: 13-04-2019

Corresponding Author: Roxanne Helm-Stevens, Azusa Pacific University California, USA

Email: rhelmstevens@apu.edu

\begin{abstract}
This paper examines the implementation of an integrative rapid prototype instructional design model within the framework of higher education. The researchers present the Hanshaw Helm-Stevens Rapid Prototyping (HHSRP) model utilized to develop online courses for two graduate programs, including 33 courses, housed in the School of Business and Management. The evaluation came after a two-year partnership between the Office of Innovative Teaching and Technology and the School of Business and Management focusing on rapid development and deployment of online courses. In a case study format, the researchers describe the adopted model, including the processes and roles contained therein and lessons learned. Based on documentation, interviews and practical observation, issues are explored through assessing and analyzing information gathered from these different sources. This research supports the possibility that there are valuable outcomes in the area of process, team composition, collaboration and communication.
\end{abstract}

Keywords: Instructional Design, Rapid Prototyping, Online Course Development

\section{Introduction}

Tripp and Bichelmeyer (1990) published a pivotal white paper exploring the viability of applying the rapid prototyping methodology to instructional design for computer-based training. Tripp and Bichelmeyer (1990) pointed to the recent successes of rapid prototyping as a design methodology in the field of software engineering claiming it solved "efficiency problems associated with traditional software design, while increasing effectiveness" (p. 31).

They argued that recent instructional design theories supported the notion that rapid prototyping was suitable as an alternative instructional design strategy. Indeed, Tripp and Bichelmeyer (1990) stated "there is always a need for instructional design methodologies which are most efficient, while maintaining or enhancing effectiveness" (1990, p. 31).

According to Derouin et al. (2005), "rapid prototyping is based on the idea that programs can be created more effectively and efficiently when modifications are made to models of programs (essentially, rapidly built prototypes) rather than to final products" (2005, p. 925). A high-level strategic approach to instructional design, rapid prototyping is characterized by the simultaneous occurrence of development, construction and utilization.

Stakeholders provide input and recommendations throughout the various iterations of development and utilization. George (2002) explains that rapid prototyping models involve Subject Matter Experts (SMEs), end-users and instructional designers interacting with prototypes in an ongoing process of continuous review and revision. Derouin et al. (2005, p. 926) claim the "process of continual development and testing allows products to be brought to users more quickly and is likely to result in products that better meet the needs of learners (in terms of usability and content)." Lee (2003) expands by stating "rapid prototyping will reduce the time required of programmers, instructional designers, authors and subject matter experts, while making that time spent more focused and useful for the courseware design and development process" (2003, p.1).

Almost twenty years have passed since Tripp and Bichelmeyer (1990) put forth their ideas on the viability of applying rapid prototyping as a methodology for instructional design. Since then, the field of instructional design has enjoyed considerable success with online course development taking center stage. Several scholars 
have attempted to implement and modify Tripp and Bichelmeyer's (1990) model, Fig. 1.

Most recently, modifications, such as those by Rieber (2007) attempt to demonstrate the continuous, non-linear nature of the rapid prototyping methodology, Fig. 2.

Yet, despite the number of efforts underway to develop comprehensive models and systems that automate the ID process, scholars and educators have failed to put forth a widely accepted rapid prototyping instructional design model. Pedersen (2004) summarizes "the rapid growth of online education has created a gap between research and practice" (p. 169). Recently, Desrosier (2011) offered an explanation, models and systems "should be interpreted and adapted not necessarily imposed literally. The difference is guidance versus prescription, the latter of which has dominated ID practices for decades" (p. 139).

\section{Rapid Prototyping Instructional Design for Higher Education}

Aust and Issacson (2005) presented their reflections on employing the rapid prototyping methodology in 50 online modules encompassing 150 lessons and over 100 hours of mediated instruction. They claimed the "effort spent developing clear specifications and requirements saved time in development efforts and minimized the need for later revisions" (p. 7). Aust and Issacson (2005) also noted the importance of extending alpha and beta testing of user interface to "all phases of production from the initial prototyping through final distribution" (p. 7). Although their study case identified the importance of clear communication and collaboration as lessons learned, Aust and Issacson (2005) did not describe the rapid prototyping process utilized or specify the roles involved in that process.

More recently, Botturi et al. (2007) claimed the rapid prototyping design model had a positive impact on largescale e-learning projects. Presenting three eLab case studies, they found fast prototyping provided an effective management platform for instructional design by increasing communication. They found the RP methodology focused team discussions, fostered the development of mutual understanding and had an overall "positive impact on e-learning project team communication" (p. 266).

Also, in Daugherty et al. (2007) presented that rapid prototyping provided a successful ID methodology for their client, "producing a high quality of instruction under time and resource constraints" (p. 7). They cited high involvement (high level of ownership from analysis to evaluation), collaborative teamwork and continuing communication as the factors that lead to the successful relationship between the client (SME) and the instructional design team. Examining the factors that contributed to successful teamwork, Daugherty et al. (2007) noted the involvement of experienced instructors and supervisors created and drove the factors that contributed to the success of the project team.

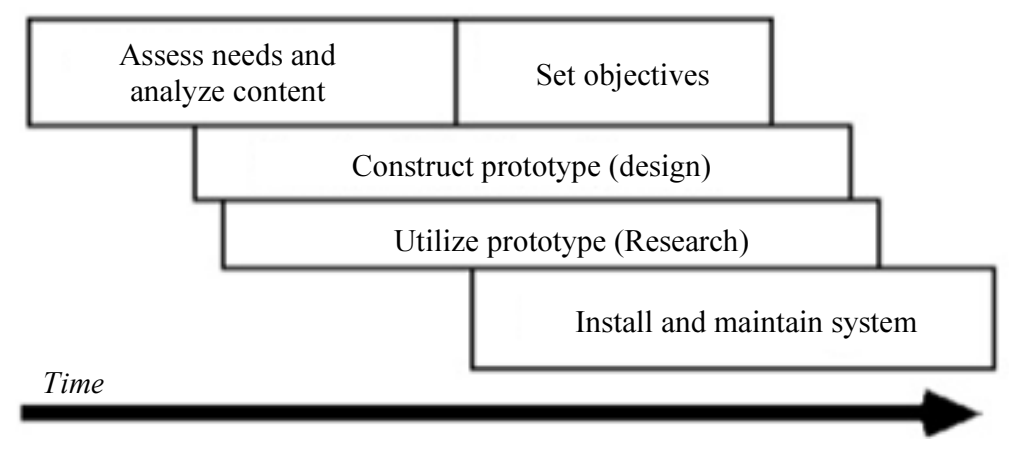

Fig. 1: Tripp and Bichelmeyer (1990)

\begin{tabular}{|c|c|}
\hline $\begin{array}{c}\text { Assess needs and } \\
\text { analyze content }\end{array}$ & Set objectives \\
\hline & Construct prototype (design) \\
\hline & Utilize prototype (Research) \\
\hline & Install and maintain system \\
\hline
\end{tabular}

Fig. 2: Tripp and Bichelmeyer (1990) as modified by Rieber (2007) 


\section{Rapid Prototyping Compared to Classic Instructional Design Models}

Unlike rapid prototyping, which allows for the simultaneous occurrence of design and development, classic instructional design models, such as the ADDIE and ASSURE methodologies, takes a linear perspective. These models prescribe a structured approach to the instructional design process by providing orderly stepby-step activities. Researchers have noted that this structured approach to instructional design emphasizes effectiveness rather than efficiency (Branson and Grow, 1987; Briggs, 1977; Briggs and Wager, 1981; Gagné, 1987; Gagné and Briggs, 1972).

Traits of traditional/classic models of instructional design:

- Characterized by heavy front-end analysis - analysis of learners, context, needs, objectives, etc

- Instructional assessments and activities are designed and developed

- Deliverable product delivered to stakeholders at end of the process

- Evaluation of product by end users provide feedback for improvements needed

- Steps in approach can be linear or iterative, but iterations usually involve the phases after deliverable launches and feedback on usage is received

Rapid prototyping, a time-compression technique, aims to complete the instructional design process in less time while using fewer resources in comparison to traditional ID approaches. Nixon and Lee (2001) found that "rapid prototyping opens up the boundaries found in traditional models (2008, p. 102). Jones and Richey (2000) expanded by stating "RP involves the development of a working model of an instructional product that is used early in a project to assist in the analysis, design, development and evaluation of an instructional innovation. The simultaneous creative and build process can dramatically reduce time and cost" $(2000$, p. 63).

Traits of rapid prototyping models of instructional design:

- Analysis performed at the front end, but less intensively than traditional models

- Mock-up/prototype of deliverable designed and delivered to stakeholders early in the process

- Stakeholders provide feedback for the prototype

- The prototype is redesigned for an additional round of feedback

- Revision cycle repeats until prototype becomes deliverable product approved by stakeholders for end user usage

- Requires more feedback from stakeholders throughout entire process
- Aims for less time for development

- Aims for less resources and money for development

- Feedback by end users provide evaluation criteria for subsequent versions

Jones and Richey (2000) state "Instructional designers are frequently confronted with demands not only to generate high-quality products but also simultaneously to reduce design and development time. One solution to this dilemma is the use of rapid prototyping methodologies" (p. 63). Nixon and Lee (2001) summarize the importance of selecting an appropriate instructional design model as they "provide structure to the project, problem solving strategies, evaluation and feedback" (2008, p. 95).

\section{Developing Rapid Prototyping Models for Higher Education}

University administrators need to adopt an online deployment models which closely resembles traditional university course delivery operations instead of classical development-focused models (Keegan et al., 2005). Jaffee (1998) expanded by stating “... the receptivity and perceived legitimacy of new educational delivery modes is strongly related to the extent to which these instructional technologies reinforce or retain the central elements of the institutionalized and identity-enhancing classroom setting" (p. 28).

Moore (1993) suggests that in order for instructional design prototyping to be successfully implemented in traditional university settings, frameworks and models need to be based on low "structure" and high "dialog." Research by Power (2008) supports that rapid prototyping instructional design models based on low structure and high dialog could indeed succeed but they must also should emulate traditional university practices and operations Similarly, the strategy of participatory rapid prototyping has been successful in universities (Collis and de Boer, 1998; Daugherty et al., 2007; and McDonald, 2006) and research institutes (Batane, 2010; Kim and Park, 2007) worldwide. Desrosier (2011) reported the University of California Santa Cruz Extension utilized RP to produce new entrepreneurship curriculum for an in-person classroom program. Replacing previously utilized exhaustive upfront ADDIE-style analysis, the participatory RP model employed a quick competitive opportunity analysis. After a failed first start, Desroiser chronicled that the initial highly-structured approach was disbanded and replaced with a low-structure, participatory approach. "Judgment replaced research. Intuition, depth of personal knowledge 
and prior firsthand experience were the primary guides of development and decision making" (p. 142).

\section{Hanshaw Helm-Stevens Rapid Prototyping Model}

The Hanshaw Helm-Stevens Rapid Prototyping (HHSRP) Model is characterized by multiple iteration and feedback loops that are designed to keep courses current through the development process, while at the same time moving from design to delivery in four to eight weeks per course. The HHSRP model utilizes the low structure and high dialogue approach outlined by Moore (1993) and supported by Desrosier (2011). The implementation of the constant iterations and continual feedback loops require high dialogue while compelling low structure to accommodate the process and ensure successful application of the model's framework.

Unlike the Tripp and Bichelmeyer (1990) model or future modifications, such as Rieber (2007), the HHSRP Model has three distinct levels that are connected through iterative feedback loops:

- School/Organizational

- Prototype Course

- Sustainment
In addition to the model's unique attributes of multiple iterations and feedback loops, one of the key differences between the HHSRP Model and previous rapid prototyping models is the sustainment level. During this phase, the low-structure framework allows for nimbleness of change. Each term the course is offered creates an opportunity to update and change the course. This flexibility is illustrated through the feedback loop to the master shell, created in the Prototype Course level (Fig. 3). This maintains the nimble prototype approach for the life of the course Fig. 4 offers an exploded view of the prototype course level.

The Hanshaw Helm-Stevens prototype model, a highly iterative process, utilizes feedback loops which are both internal to an individual level and external which connect the different levels. The three levels go beyond the course design process and look at the design and delivery process from a systems perspective. This vantage point allows for leverage of all of the opportunities found within the iterations by sharing/implementing the findings directly to multiple classes to ensure a better student experience, as well as ensuring the constant improvement and updating of individual courses as best practices emerge and business needs change. Viewing the process holistically allowed for the simultaneous focus of organizational, student and instructor needs.

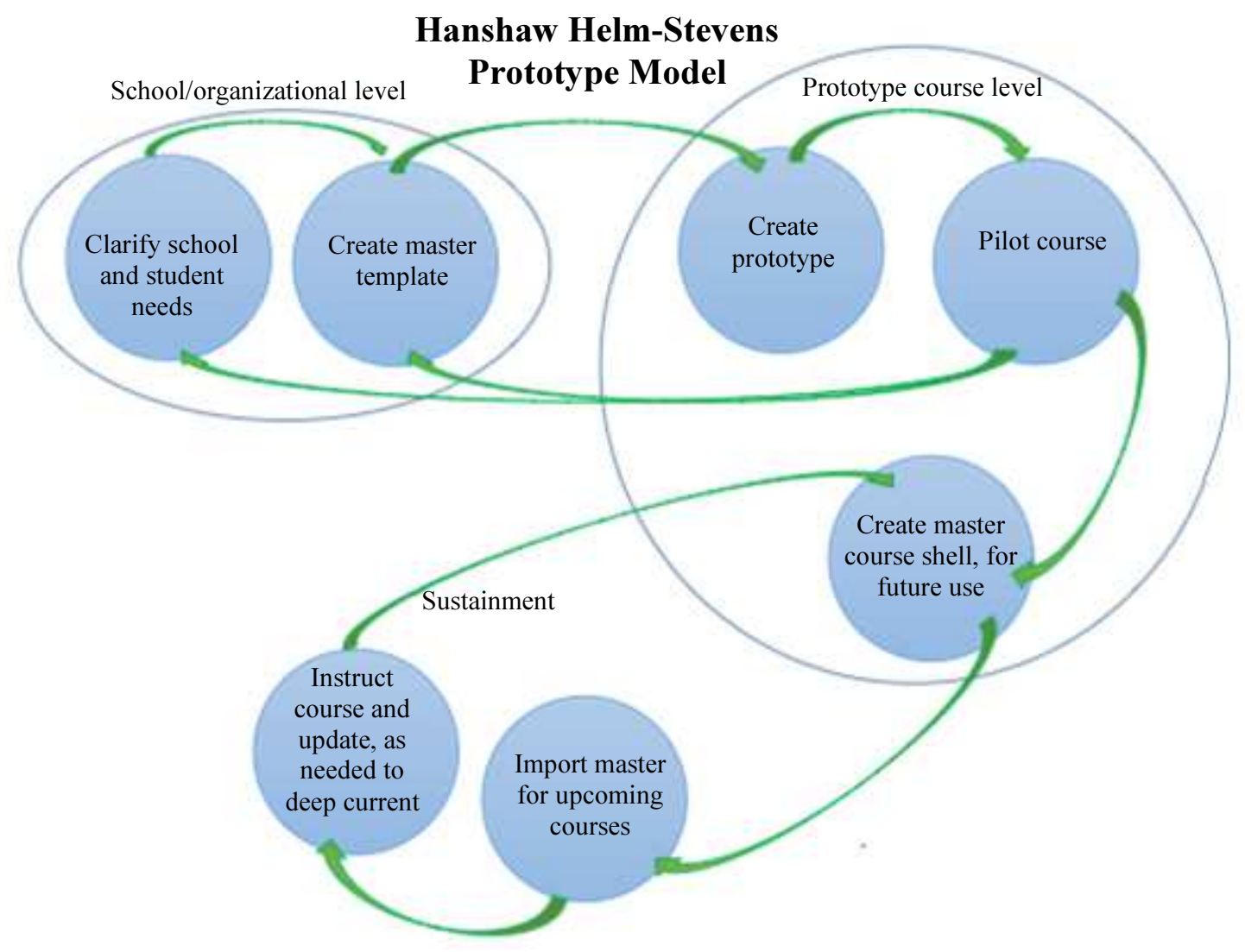

Fig. 3: Hanshaw Helm-Stevens Rapid Prototype Model (HHSRP) 


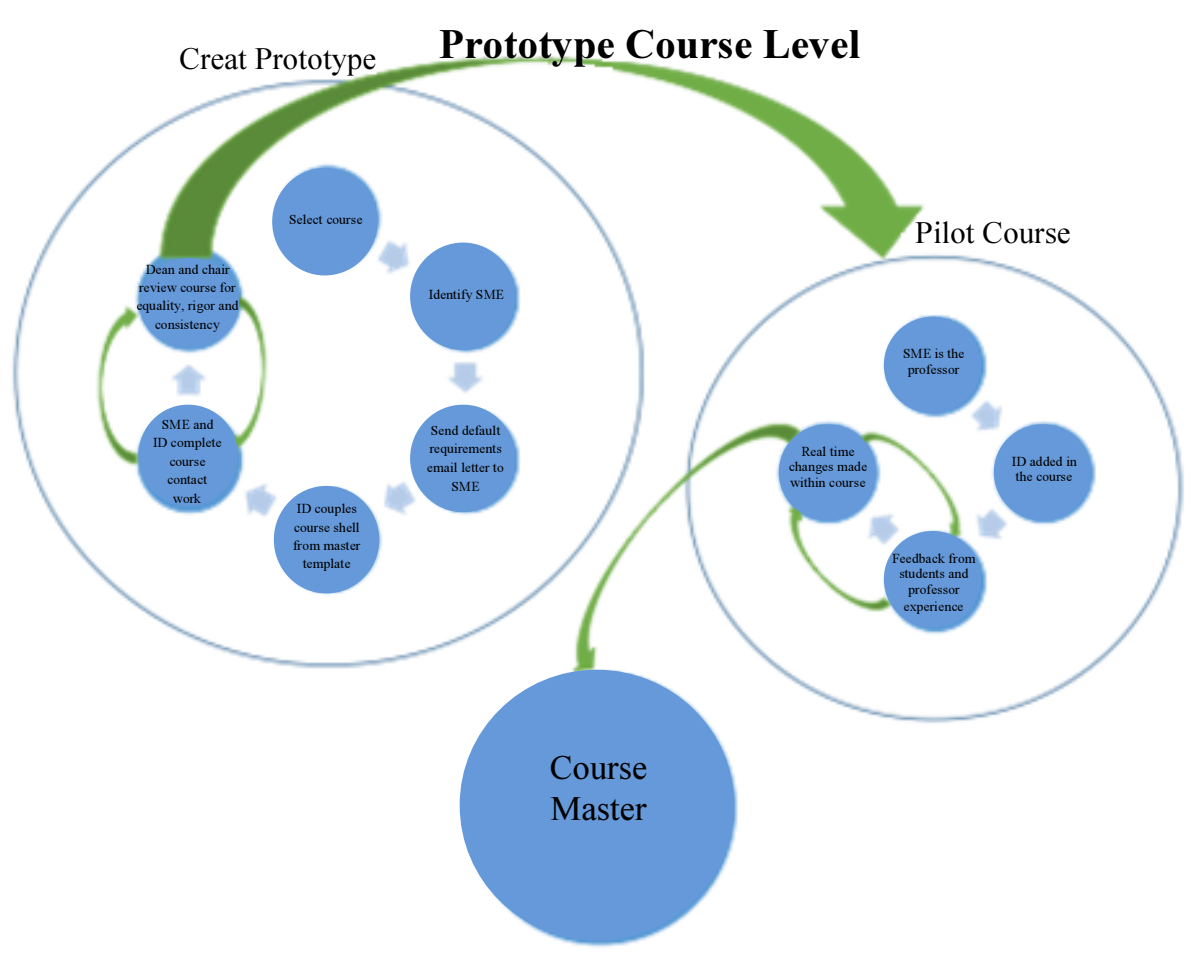

Fig. 4: Exploded view of prototype course level

\section{Problem}

The School of Business and Management was tasked with creating online programs for the Master of Business Management and Master of Business Administration programs. The Master of Business Administration (MBA) program encompassed 14 courses in the areas of finance, accounting and marketing. The Master of Business Management (MBM) program encompassed 19 courses across the management sciences, including human resources, employee development and organizational development and change. Both programs included a combination of new curriculum courses in need of development and revisions of previously developed online courses.

Mandated time frames required courses be designed and built quickly. However, the school also required a consistent look and feel in order to establish a consistent student experience, wanting the students to focus on learning rather than locating course and assignment material. The fast paced time frame necessitated that course design and build occur simultaneously. The simultaneous template design and course development compelled flexibility as individual courses within the programs would be changed and updated constantly.

\section{Case Study}

During the 2017-2018 timeframe, Azusa Pacific University utilized the Hanshaw Helm-Stevens Rapid
Prototyping instructional design model to produce two online graduate programs housed in the School of the Business and Management. This case study examines the implementation of the HHSRP model.

The Office of Innovative Teaching and Technology and the School of Business and Management formed a two-year partnership to spearhead the project, focusing on rapid development and deployment of online courses. While the Office of Innovative Teaching and Technology core team remained consistent throughout the project, the School of Business and Management elected to have two different leaders-the MBA department chair would lead the MBA project, the MBM department chair would lead the MBM project.

\section{Time Constraints}

The timeframe set by the School of Business and Management (SBM) was deadline-driven. This precluded the use of a traditional ID approach as the typical timeframe for traditional development of a course for delivery is more than three months. SBM program courses needed to maintain a development schedule of eight weeks in order to debut the programs in the upcoming academic year.

\section{Roles and Responsibilities}

There were three key roles in the instructional design process: The dean, the department chair and the instructional designer. The Dean was initially involved 
in the design of the overall look and feel of the course template as well as defining the conceptual level of rigor required in each course. Once this was established, the SBM Dean kept involved in the process by being the final quality check. Department chairs selected the SME and made initial contact.

Once the department chair contracted the Subject Matter Expert (SME) and the SME agreed to the requirements of the SME role, the initial task of the designer was to provide a course shell and Learning Management System (LMS) training. The designer provided any training necessary for the SME to be able to input and edit educational content within the LMS. The streamlined process eliminated the typical backand-forth workflow, this reduction of small item LMS development was essential to the efficiency of the design process. The ability of the SME to work directly in the LMS was a critical element in reducing development time.

After the SME supplied the content, the designer's attention turned to ensuring that the materials were presented consistently within the learning environment and accessible by students.

\section{Process}

A highly iterative process, the Hanshaw HelmStevens prototype model is characterized by feedback loops in all three levels-school/organizational, course prototype and sustainment. These three levels go beyond the course design process and look at the design and delivery process from a systems perspective. Viewing the process holistically allowed for the simultaneous focus of organizational, student and instructor needs. This vantage point allows for leverage of all of the opportunities found within the iterations by applying and embedding the findings directly to multiple classes, those in the prototype stage and those already built. The key benefits of this approach allows for continuous and constant improvement, flexibility and rapid adaptation of improvements.

\section{School/Organizational Level}

Key Objectives:

- Determine MBA and MBM program requirements

- Establish processes and responsibilities

- Decide upon instructional design methodology

- Design Master Template to facilitate a consistent learner experience

Key Roles:

- Dean

- Department Chair

- Instructional Designer
Initially, there was a meeting between the Dean, MBM Chair, ID supervisor and ID. During this initial meeting, the needs of the school of business were expressed and ideas on how the ID team could meet those needs were discussed. One of the key elements of this level is standardization and templatizing.

By the end of the meeting, the needs of the school were clearly identified and an initial instructional design model was agreed upon. It was agreed to prototype the initial course. Three key decisions were made. A specific template would be created to give the learners a consistent experience. To achieve this goal, the number of people working in the course shell would be purposefully limited to the SME and instructional designer. The dean and department chair would retain final approval on content and course development.

Once the general layout was finalized, the first course for both programs started development. It was decided that the dean would work with the instructional designer in developing the first course of the MBA and MBM programs. The dean worked closely with the instructional designer in developing the teaching materials, including appropriate rigor level and assessment strategies.

One of the primary concerns at the organizational/school level was creating a consistent student experience throughout the program. A consistent online learning experience for the student was deemed as critical by the Dean and Chair because they correlated the experience with better student outcomes.

Creating a consistent student experience meant that there was standardization of some elements. For example, where documents or materials were housed was standardized. There was standardization created in the discussions boards as well. For example, the due date of the initial discussion and responses were standardized throughout the program. This was especially helpful for students because they no longer had to figure out when discussions were due from class to class. A discussion rubric was also created and utilized for the entire program. This helped create a more consistent experience for students in different sections of the same course as well as throughout the entire program.

Another notable contribution to creating a consistent learning experience for the students is the use of the "ez access" format for the course. Ez access included using labels and icons that stated "read, watch, discuss, do, quiz". This consistency helped students and professors in the course as well as helped the SME and ID create the course. Even though the content was different depending on the course the "feel" of the class remained constant.

At times, when implementing standard practices, innovation and creativity are limited. This was not the case. The opposite is actually true. When the mundane chores of design were standardized and already inserted into the course shells, time and energy were actually freed up and the professors or SME's spent more time drilling deeper into the content and thinking of creative 
ways to facilitate the students learning of the content. It seemed the energy that would have been expended on the mundane tasks was now being spent on better teaching and learning practices. This was seen as the greater use of multimedia throughout the courses along with multiple different methods to apply the content being learned.

\section{Prototype Course Level}

Key Objectives:

- Create Prototype

- $\quad$ Pilot the prototype course

- Create master course from adjusted prototype pilot

Key Roles:

- Dean

- Department Chair

- Instructional Designer

- $\quad$ SME

The first step of this level entailed the instructional designer creating a design blueprint mock-up which contained agreed upon program-standard layout, including key features and components. This mock-up was iterative, as the dean and the department chair provided feedback and suggestions for additional template features.

After receiving approval on the blueprint, the instructional designer created a design template within the LMS, which contained placeholders for various elements of each course. This design was also an iterative process, as the design received feedback from the dean and the department chair. It should be noted that the feedback provided for both the blueprint and the course template was limited to three key roles-the dean, department chair and instructional designer. Limiting the stakeholders involved in this phase was intentional in order to focus on quicker progress rather than to include more voices which may likely have slowed this phase.

The creation of the prototype course for the pilot course and the prototype course and process were highly iterative and several areas overlapped as changes in one created change in the other. This is illustrated by the internal and external feedback loops shown in Fig. 1. At times there were simultaneous changes happening to the process and product in order to keep pace with the requirements of the program and come up with a usable prototype at the end of the pilot class. For this reason, there may be occasions when the term pilot or prototype will be used interchangeably.

The first prototype course was purposefully created with the Dean and Department Chair with the intent of creating a course shell that contained the necessary components to act as a development master. The development master did not contain content but contained the agreed upon design principles and key features to ensure a consistent experience for the learner. The prototype was then transitioned to a pilot course where the dean served as the SME because the course would serve as the template or master for the development process while the master shell would serve as the template within the development process.

Following this set of protocols, utilizing a pilot and master shell simultaneously, required each change to be executed in the master shell and pilot course as we went through the pilot process. But this also allowed for quality control and time savings on the back end since adjustments were made in the class pilot and the master shell simultaneously.

The process was finalized and codified and would be managed by the department chair. The MBM department chair developed an initial contract for the Subject Matter Expert (SME). The SME letter, as it came to be known, explicitly defined the requirements of the course design and outlined the role of SME throughout the process. The SME letter also defined the decision parameters for the department chair, SME and the instructional designer. The initial contact with the SME is now seen as one of the critical touch points for maintaining quality within courses and driving the fast-paced workflow. The clarity provided by the SME letter created an effective decentralized command structure for decision making.

While communication styles and responsiveness varied between various subject matter experts, the steps for the course development remained consistent between the instructional designer and the subject matter expert. A key to the success of the next course developments was that the expectations and communication processes gleaned from the initial course development were to be clearly communicated by the department chair to the assigned subject matter expert prior to the collaborative work between the subject matter expert and the instructional designer.

\section{Sustainment}

Key Objectives:

- Import the course prototype to a course "Dev Master" (the shell that future offerings of the course will be copied from)

- Facilitate multiple sections of the class

- Update course as needed to remain current and relevant

- If individual course is updated make the same changes to the "Dev Master"

Key Roles:

- Dean

- Department Chair

- Instructional Designer

- Professor 
The sustainment level was purposefully maintained to continually receive feedback from the professors and students in order to maintain relevancy and recency of course materials. The feedback loop is illustrated in Fig. 1. This purposeful feedback maintained the "Dev Master" as a living prototype much like the process in the manufacturing of high-performance air vehicles. In manufacturing, prototypes are constantly changed in order to come up with ways to create better product performance and capabilities. The authors approached the course performance from a learning performance perspective that mimicked a prototype process in the manufacturing environment.

This approach was useful for several reasons. It allowed the authors to receive feedback from the micro (course level) and macro (organizational/school level) from multiple stakeholders.

\section{Effectiveness}

The initial course prototype was completed within a 3 -week time span and taught in the upcoming term. The course was updated according to feedback the SME/Professor received about the course. Changes were made in real time in the prototype course being offered. Once the course was concluded the prototype was copied without student information into a "dev Master" course shell.

For the initial block of courses being transformed using the HHSRP model consisted of 14 classes. Eleven of the classes were built within the 8-week timeframe and passed the rigor and consistency quality assurance checks by the Dean and Chair. The 11 classes that passed the quality assurance checks from the Dean and Chair were created utilizing a low-structure and high-dialogue approach. These 11 SME's felt a sense of clarity with the process. Due to the high-level of dialogue, the SMEs were able to understand the goals, focus on course development tasks and meet deadlines.

Three of the initial 14 courses did not pass the Dean's quality assurance check. These courses did not utilize a high dialogue approach. The Chair with oversight responsibility for these three courses utilized a lowstructure and low-dialogue approach. This approach failed in part due to the lack of critical communications, communication stages and steps were either shortened or deleted. These courses had to go back through different portions of the process requiring additional effort, time and use of resources. Eventually, these courses all passed the Dean and Chair's quality assurance checks for rigor and the student experience.

\section{Iterations from Feedback Loops}

The process for making course updates was simple, with two categories of updates-minor updates and major updates. Minor updates included assignment or project changes in due dates, new article readings, new videos, revised discussion prompts and correction of malfunctioning links.

Minor Updates:

- Before the start of a new term, any minor ID updates for the course would be communicated by the instructor to the ID and the department chair

- The ID would update the master course

- The ID would copy the master course into the upcoming term's course shell for the instructor

Major updates included textbook changes, learning outcome changes and curriculum or course content revisions.

Major Updates:

- Before the start of a new term, any major updates would be communicated by the instructor to the department chair

- The department chair would review and approve requested changes or revisions to the course

- Upon approval, ID would make updates to the master course

- The ID would copy the master course into the upcoming term's course shell for the instructor

The iterative nature of the RPD process was helpful in revealing key needs and also bringing forward opportunities for improvement:

- Use of a "pre-flight checklist" for instructors. The preflight consists of directions for instructors to start taking specific learner engagement actions 2 weeks prior to course start. The preflight checklist also contains step-by-step directions for personalizing the classroom and publishing the course. The preflight also contained best practices and expectations for teaching online courses

- Several student-centered changes were added, such as helpful links and community center tabs and examples of A grade assignments

- A gateway quiz was developed and embedded into each course

\section{Discussion}

Although the MBA and MBM department chairs operated under the same process and worked with the same ID team; yet, both teams experienced different levels of success. The MBA team experienced both success and failure; however, the failures stopped or slowed the instructional design process. The MBM team also experienced both success and failure; however, the MBM team was able to overcome those setbacks and utilize them to innovate and improve the process and deliverable. 
Differences in MBA and MBM team success and failure levels were examined utilizing frameworks from Moore's (1993) research and Daugherty et al. (2007) research.

\section{Low Structure and High Dialog Configuration}

Utilizing Moore's (1993) research claiming in order to successfully deploy instructional design prototyping in traditional university settings, frameworks and models need to be based on low "structure" and high "dialog," both the MBA and MBM ID/Department Chair teams utilized a low structure approach. Yet, the degree of low "structure" varied. The low-structure approach utilized by the MBA department chair ceased at the hiring of the SME. Whereas, the low-structure approach utilized by the MBM department chair included outlining the project scope, responsibilities and decision-making parameters and overseeing the process. The MBM department chair followed the SME hiring with a detailed SME letter and employed touch point meetings throughout the process. These meetings ensured that decisions were made and implemented quickly between the department chair, subject matter experts and the instructional designer. There was minimal confusion or disagreement over processes or responsibilities.

Regarding communication, the MBA department chair utilized a low "dialog" approach, whereas the MBM department chair utilized a high "dialog" approach. As noted, each instructional design project was started through the use of a clear and detailed SME letter. This initial communication from the MBM department chair included the subject matter expert, instructional design team and administration-all stakeholders were included in the first communications. The high dialogue set the stage for everyone to be seen as partners, working together to ensure the success of the course design and delivery. The clear and transparent requirements and expectations created in the initial stage of building the first prototype were continually reinforced. Communication of the process and communication between all stakeholders was a critical piece of the success of the MBM project.

In the MBA program, there were two occasions where the initial detailed SME letter did not go out to the SME. Instead, an abbreviated letter was sent to the SME. Each time, this had a negative effect on the process in three ways. First, since the role of the SME was not defined clearly, both SMEs were initially confused regarding their role and responsibilities. This initially slowed down the process. Second, decisions regarding course content stalled because the parameters of what decisions could be made and to what extent was not clear. Third, SBM design standards were not communicated. This resulted in the SMEs changing part of the standardized design of the master course shells requiring the course designers to re-do design work previously completed. Both SMEs hired were unfamiliar with the university, its vision and mission, or course development requirements. In the worst case, the SME was unable to fulfill all requirements.

\section{High Involvement, Collaborative Teamwork and Continuing Communication}

In addition to Moore's framework of low "structure" and high "dialog," additional differences existed between the approach utilized by MBA and MBM department chairs. Discussing their research findings, Daugherty et al. (2007) claimed high involvement (high level of ownership from analysis to evaluation), collaborative teamwork and continuing communication as the factors that lead to the successful relationship between the client (SME) and the ID team.

Partnering with high dialog, the MBM team experienced high involvement. Acting as the hub, the MBM chair continued to oversee the process as it matured. After hiring the SME, typically a faculty member with a doctoral degree or a senior faculty member, the MBM Department Chair approved the proposed course syllabus prior to course design, this helped to signal and alert any potential issues, such as duplicate assignments or textbooks in the program.

Remaining involved through the process, the MBM department chair made the decision to have the SME teach course first time offered. This decision allowed for an additional quality check of the course by the SME and ultimately proved valuable. This direction allowed the SME to experience their course design and make revisions and adjustments as necessary. The requirement to have the SME be the first professor to teach the pilot course and to have the instructional designer available to make changes of any type within the live course proved to be highly beneficial. This process alleviated the professor from having to go through the support desk process to have any changes made and alerted the instructional designer to any issues that may resurface in upcoming courses. This process also allowed the instructional designer to take full advantage of the RPD design process even through the initial pilot course. Typically, issues driving changes revolved around how the learner experienced the course; however other findings lead to iterations that provided value.

The high dialogue and high involvement structure of the MBM team fostered efficient and collaborative teamwork. Every member of the team was included in communications to facilitate working together. If or when an issue arose, the clear communication ensured that the department chair and instructional designer were alerted to any potential issues and able to brainstorm potential solutions.

Clarity of communication along with a structured and a unified vision were critical supporting components of the success of the MBM team. The consistent and 
unified vision along with clear communication created a healthy team that operated within a clearly defined structure with a high level of ability to make decisions and adjustments as necessary. The unified vision and clarity of communication created a team that had the ability to work closely and quickly, with clearly defined goals, roles, tasks, responsibilities and authority. Thus, decisions could be made without the need for multiple meetings.

In the MBA program, there were two instances, post prototype, within the course development process, post prototype, where issues in the course development were directly felt by the team and the school. Both issues stemmed from a lack of direction with the SME and resulted in missed deadlines. Moreover, the lack of clear communication, specifically what decisions and the parameters of the decision making that was within the realm of the SME, caused excess work because the SME's began attempting to design the course look and feel rather than provide course content. This lack of clarity cost excessive time and money due to the necessary rework.

\section{Experienced Instructors and Supervisors}

In addition to the factors of high involvement, collaborative teamwork and continuing communication, Daugherty et al. (2007) noted that experienced instructors and supervisors were the critical bedrock factors necessary to form the platform-high involvement, collaborative teamwork and continuing communicationthat led to the success of the project.

Team composition was a key factor in understanding the varying success levels between the MBA and MBM programs. Team composition differed in two critical areas - hard skills (technical competence) and soft skills (communication and project management). In addition to high communication competence, the MBM team possessed deep project management skills, education and experience in instructional design and management experience leading instructional design teams.

Because online course design affords many of the same instructional design principles and strategies as face-to-face classes, it was helpful to have both the ID and the department chair understand instructional design and development on the MBM team. In addition to years of instructional design experience, this team held certifications in curriculum development and course redesign.

When interviewed, the ID, who remained consistent in both teams made note of Lencioni's four-discipline model as a factor in the success of the MBM program. The four-disciplines: build a cohesive leadership team, create clarity, over-communicate clarity and reinforce clarity (Lencioni, 2002).

\section{Limitations}

This research was conducted in case study format. Although qualitative research was gathered and analyzed, an empirical examination of the Hanshaw
Helm-Stevens Rapid Prototyping instructional design model is required to quantify successes and failures. Additional research regarding the complexities of the low structure, low dialogue and low structure, high dialogue dimensions may reveal the intensity and strength of each dimension.

Moreover, this research was conducted in a contained setting-a two-year partnership between two departments within the university, CTLA and SBM. As noted, CTLA team composition remained constant; however, SBM team composition changed from the MBA to the MBM. Although skill set and leadership approach differences were diagnosed, this research did not explore or account for individual factors, such as personality traits with regards to team success and failure. Similarly, this research did not explore the interactions of personalities within team composition or any possible contributions or impediments of those interactions to team successes and failures.

\section{Conclusion}

The HHSRP model was the key design principle that allowed the cross-functional teams to design, develop and upgraded the MBM and MBA program courses. The rapid prototyping model and accompanying processes were found to be an effective way to implement changes quickly and meet the needs of the School of Business and Management and their students.

The highly iterative RPD process is part of the reason for the success of the design. However, because the iteration process required high involvement, a collaborative work environment, flexibility and good communication channels the success levels differed between the MBA and MBM teams. Both department chairs experienced different levels of success. Although the ID was consistent in both teams, team composition changed in the area of skillset and leadership approach. As with any process, clear roles and communication between each role is critical to success. Additionally, team composition requires careful consideration to experience, education and skillset. This study presented the lessons learned as this model was consistently implemented in both programs. Thus, the findings in this case study support the research by Moore (1993) and Daugherty et al. (2007).

Further research is needed to improve the model and processes and determine their validity, such as an empirical study of the model's success. Additionally, further research is needed in the areas of competencies for cross-functional instructional design team supervisors and members.

\section{Acknowledgement}

The authors acknowledge the support of the School of Business and Management and the Center for Teaching, Learning and Assessment. 


\section{Author's Contributions}

Dr. Helm-Stevens: Contributed to the literature review, discussion, limitations, lessons learned and design of model. Dr. Helm-Stevens also prepared the draft manuscript.

Dr. Hanshaw: Created the model design, collected data, and lessons learned. Dr. Hanshaw also lead the process and sustainment documentation and contributed to the discussion.

Joseph Kim: Contributed to the literature review, process, sustainment and documented model stages.

\section{Ethics}

This article is original and contains unpublished material. The corresponding author confirms that all of the other authors have read and approved the manuscript and no ethical issues involved.

\section{References}

Aust, R. and R. Isaacson, 2005. Designing and evaluating user interfaces for elearning. Proceedings of World Conference on E-Learning in Corporate, Government, Healthcare and Higher Education, (HHE' 05), Chesapeake, VA: AACE, pp: 1195-1202.

Batane, T. 2010. Rapid Prototyping For Designing and Delivering Technology-Based Lessons. In: Educational Media and Technology Yearbook, Orey, M., S. Jones and R. Branch (Eds.), Springer, Boston, MA, ISBN-10: 978-1-4419-1516-0, pp: 45-55.

Botturi, L., L. Cantoni, B. Lepori and S. Tardini, 2007. Fast Prototyping as a Communication Catalyst for ELearning Design. In: Making the Transition to ELearning: Strategies and Issues. Bullen, M. and D. Janes (Eds.), Hershey, PA: Idea Group, pp: 266-283.

Branson, R.K. and G. Grow, 1987. Instructional Systems Development. In: Instructional Technology: Foundations, Gagné, R. (Ed.), Lawrence Erlbaum Associates, Hillsdale, NJ, pp: 397-428.

Briggs, L.J. and W.W. Wager, 1981. Handbook of procedures for the design of instruction. Educational Technology Publications, Englewood Cliffs, NJ.

Briggs, L.J., 1977. Instructional Design. Englewood Cliffs, 1st Edn., Educational Technology Publications, NJ.

Collis, B. and W. de Boer, 1998. Rapid prototyping as a faculty-wide activity: An innovative approach to the redesign of courses and instructional methods at the University of Twente. Educat. Media Internat., 35: 117-121.

Daugherty, J., Y. Teng and E. Cornachione, 2007. Rapid prototyping instructional design: Resisting the ISD model. Proceedings of the International Research Conference in the Americas of the Academy of Human Resource Development. Indianapolis.
Derouin, R.E., B.A. Fritzsche and E. Salas, 2005. Elearning in organizations. J. Managem., Sage Publish., 31: 919-940.

DOI: $10.1177 / 0149206305279815$

Desrosier, J. 2011. Rapid Prototyping Reconsidered. The J. Continu. Higher Educat., 59: 135-145.

Gagné, R.M., 1987. Instructional Technology: Foundations. Lawrence Erlbaum Associates. Hillsdale, NJ.

Gagné, R.M. and L.J. Briggs, 1972. Principles of Instructional Design. 4th Edn., Harcourt Brace Jovanovich College Publishers, ISBN-10: 0030347572, pp: 365. New York: Holt, Rinehart and Winston.

George. S., 2002. Instructional design in elearning. Elearnspace.

http://www.elearnspace.org/Articles/InstructionalDe sign.htm

Jaffee, D., 1988. Institutionalized resistance to asynchronous learning networks. J. Asynchronous Learn. Netw., 2: 21-32.

Jones, T.S. and R.C. Richey, 2000. Rapid prototyping methodology in action: A developmental study. Educat. Techn. Res. Develop., 48: 63-80.

Keegan, D., E. Schwenke, H. Fritsch, G. Kenny and G. Kismihok et al., 2005. Virtual classrooms in educational provision: Synchronous elearning systems for European institutions. ZIFF PAPIERE 126. Zentrales Institut fur Fernstudienforschung (ZIFF), Fern Universitat, Hagen, Germany.

Kim, E. and J. Park, 2007. Study on the rapid prototyping methodology of the lecture content for the IT SoC certificate program. Proceedings of the IEEE International Conference on Microelectronic Systems Education, (MSE' 07).

Lencioni, P., 2002. The Five Dysfunctions of a Team, Jossey-Bass, ISBN-10: 0-7879-6075-6

Lee, J.E., 2003. Rapid Prototyping of Courseware. Knowledge Management Solutions, Inc.

McDonald, J., 2006. Participatory Prototyping: Improving Faculty Involvement in TechnologyMediated Instruction. In: Current Developments in Technology-Assisted Education, MéndezVilas, A., A. Solano-Martín, J.A. Mesa-González and Mesa-González J. (Eds.). Formatex, Badajoz, Spain, pp: 1898-1902.

Moore, M.G., 1993. Theory of Transactional Distance. In: Theoretical Principles of Distance Education, D. Keegan (Ed.), Routledge, New York, pp: 22-38.

Nixon, E. and D. Lee, 2001. Rapid prototyping in the instructional design process. Performance Improvem. Quarterly, 14: 95-116.

Pedersen, S., 2004. Designing and researching enhancements for online learning: A commentary on Veal, Brantley and Zulli. Contemporary Issues Technology Teacher Education, 4: 163-172. 
Power, M., 2008. The emergence of a blended online learning environment, MERLOT J. Online Learn. Teach., 4: 503-513.
Tripp, S. and B. Bichelmeyer, 1990. Rapid prototyping: An alternative instructional design strategy. Educat. Technol. Res. Develop., 38: 31-44. 